\title{
Modos de pensar dos profissionais do Programa Academia da Saúde sobre saúde e doença e suas implicaçóes nas açôes de promoção de saúde
}

\section{I ${ }^{1}$ Ana Mônica Serakides Ivo, ${ }^{2}$ Deborah Carvalho Malta, ${ }^{3}$ Maria Imaculada de Fátima Freitas I}

Resumo: O Programa Academia da Saúde (PAS) foi criado para contribuir com a promoção da saúde, produção do cuidado e melhoria do acesso à prática de atividade física, a partir da visão holística do cuidado. Objetivo: compreender representaçóes de profissionais do PAS sobre saúde/doença, que fundamentam as atividades de promoção à saúde, dirigidas à população. Metodologia: estudo qualitativo fundamentado na teoria das Representaçóes Sociais, entendendo-as como pontos de vista, explicitados na ação humana. Entrevistas em profundidade, com profissionais de educação física do PAS de Belo Horizonte, foram interpretadas pela Análise Estrutural de Narração. Resultados: existem representações centrais que definem a saúde como o oposto à doença, representaçóes periféricas, sendo saúde mais do que ausência de doença. O modelo biomédico presente convive com pontos de vista que ampliam a prática em saúde, voltada para a construçáo da promoção da saúde como um bem e um direito. Para manterem paralelas estas representações, os profissionais se utilizam, contraditoriamente, do discurso oficial que criou o Programa, ancorado na Saúde Coletiva, e do discurso da ciência e do senso comum, ancorados na Biologia. A implicação do profissional nas açôes torna-se paradoxal, exigindo melhorias em sua formação para continuar a mudança de paradigma na atenção à saúde.

> Palavras-chave: promoção da saúde; políticas públicas; pesquisa qualitativa; Saúde Coletiva; avaliação de programas.

\author{
1 Escola de Enfermagem, \\ Universidade Federal de Minas \\ Gerais. Belo Horizonte-MG, Brasil \\ (amsivo@hotmail.com). \\ ORCID: 0000-0003-4479-4474 \\ ${ }^{2}$ Escola de Enfermagem, \\ Universidade Federal de Minas \\ Gerais. Belo Horizonte-MG, Brasil \\ (dcmalta@uol.com.br). \\ ORCID: 0000-0002-8214-5734 \\ ${ }^{3}$ Escola de Enfermagem, \\ Universidade Federal de Minas \\ Gerais. Belo Horizonte-MG, Brasil \\ (peninhabh@yahoo.com.br). \\ ORCID: 0000-0002-0273-90-66
}

Recebido em: 15/05/2018 Revisado em: 06/12/2018 Aprovado em: 21/12/2018 


\section{Introdução}

A promoção da saúde é uma das principais estratégias para reduzir fatores de risco à saúde. A saúde e a doença são produçôes sociais e as Doenças Crônicas Não Transmissíveis (DCNT) apresentam-se, por excelência, como doenças condicionadas e determinadas socialmente (BUSS; PELEGRINI FILHO, 2007). A promoção da saúde combina políticas públicas e açôes nas comunidades com o intuito de melhorar a saúde e a qualidade de vida das pessoas (ALMEIDA; ATHAYDE, 2015), o que é fundamental para a proteção e o controle dos riscos de DCNT na população.

No Brasil, dentre as políticas públicas de promoção da saúde para proteção e controle das DCNT, encontram-se as açôes relacionadas à prática regular de atividade física (AF) que vêm crescendo nos últimos anos, apoiadas em evidências científicas (BARENGO et al., 2016; MORA et al., 2007) e em experiências bemsucedidas de prática de AF no contexto comunitário surgidas em algumas cidades brasileiras (BRASIL, 2013; REIS et al., 2010). Estes estudos evidenciaram ser a AF uma ferramenta de promoção da saúde, pois propicia melhoria da qualidade de vida da população, no lazer e nas relaçôes pessoais, além de diminuir o risco de adoecimento e contribuir nas medidas de prevenção secundária e terciária das DCNT. O Ministério da Saúde instituiu, por meio da Portaria GM/MS 719, de 7 de abril de 2011, o Programa Academia da Saúde (PAS) com o objetivo de aumentar o apoio às açóes de promoção da saúde da população, com base holística e transversal para as ações de saúde, cara aos princípios e diretrizes do Sistema Único de Saúde (SUS), como universalidade, integralidade e, sobretudo, equidade. Este último encontra-se na melhoria de acesso à população menos favorecida a este tipo de ambiente de promoção da saúde.

O PAS conta atualmente com mais de 2.300 polos no Brasil. Algumas cidades brasileiras que já haviam implantado algum programa semelhante tiveram maior facilidade em implementá-lo e contam com grande número de polos. Belo Horizonte, capital de Minas Gerais, passou por esse processo ao longo dos anos 2000 e é um exemplo de organização do PAS. Contava, em 2011, com 44 polos e hoje tem 77 (BRASIL, 2018). Para tanto, incluiu mais de 130 profissionais de educação física, por meio de concurso público, na rede de atençáo básica do município, o que ocorreu também nos diferentes municípios brasileiros, em maior ou menor grau. Estes profissionais estão distribuídos em diversas frentes de atenção à saúde, como nos 
núcleos de apoio à Saúde da Família (NASF), Saúde Mental, Lian Gong, Programa Qualidade de Vida do Trabalhador e, principalmente, no Programa Academia da Saúde (LAS CASA et al.; 2014).

Para a rede de atenção à saúde e para o profissional de educação física (PEF), esta foi uma novidade que demarcou expansão no campo de trabalho, novas relaçóes com outros trabalhadores e com a clientela, e novas práticas e tecnologias. O PEF que, historicamente, teve sua formação e prática profissionais atreladas à área da educação, do esporte e da aptidão física, passou a atuar no campo da saúde. Sua formação, porém, não incluía este novo espaço de trabalho e não lhe permitiu, em um primeiro momento, um entendimento claro sobre sua atuação profissional Estes profissionais foram incorporados, por meio do PAS, na produçáo do cuidado e na promoção da saúde visando à autonomia dos sujeitos, mas com formação e vivências distantes do SUS (GUARDA et al., 2014).Apesar disso, os PEF foram inseridos e estão na rede de serviços de saúde diariamente e construíram suas formas de atuação. Lacunas devem estar sendo preenchidas com a prática cotidiana, mas as contradiçôes surgem, o que pode impedir investimentos destes profissionais, de forma positiva, para o cumprimento da promoção da saúde dentro dos princípios e diretrizes do SUS. Pressupóe-se, portanto, que as capacidades gerais advindas de suas práticas e formaçóes profissionais, assim como das relaçóes com outros profissionais da atenção básica, contribuem para sua inserção no PAS de Belo Horizonte. Assim, pode haver, por parte destes profissionais, mais ou menos compromisso com os preceitos da promoção à saúde, porque trazem consigo representaçôes de saúde e doença, de prevenção, de cuidado de saúde, que não necessariamente são coerentes com estes preceitos.

Pergunta-se, então, como os PEF têm se incorporado neste novo campo de conhecimento e atuação profissional, bem como sobre quais os fundamentos se explicitam, por meio de suas representaçôes, para se definir seus modos de implicação no Programa. Assim, este estudo visa compreender representaçôes sobre saúde e doença de profissionais de educação física, que fundamentam suas atividades de promoção da saúde no Programa Academia da Saúde.

\section{Métodos}

Estudo qualitativo que busca a compreensão de um evento, fato ou experiência social pela experiência particular dos sujeitos e pela interpretação do significado que as pessoas dão a eles, expressas em suas construçôes intersubjetivas (MINAYO, 
2012). Apoiado na vertente sociológica construtivista da teoria das representaçôes sociais, proposta por Giami e Veil (1997), que define as representaçóes como pontos de vista dos sujeitos sobre determinado objeto, que são construídos em processos sociopsíquicos como elaboraçôes compartilhadas e introjetadas pelos indivíduos no cotidiano. As representaçôes mostram as formas que os sujeitos sociais criam, aderem, investem ou não nas proposições de determinado campo de ação, como é o da saúde (MÁSSIMO; SOUZA; FREITAS, 2015). Estas são, portanto, a expressão verbal e de posturas em relação ao Programa em pauta que explicitam a implicação, ou seja, o que une estes sujeitos a determinado projeto (LOURAU, 2004).

O estudo foi realizado em Belo Horizonte, com profissionais do PAS, distribuídos em três níveis, de acordo com as atribuiçōes de cada grupo: a) Coordenação Pedagógica (CP): auxilia na construção de novas açóes e diretrizes que orientam a prática dentro do programa, nas capacitaçóes dos profissionais da assistência, monitoramento e avaliação do Programa; b) Coordenaçôes Distritais (CD): referência para os profissionais da assistência em cada uma das nove regionais. É o elo entre esses e a coordenação pedagógica; c) Profissional da Assistência (PA): responsável pelo atendimento direto ao usuário. Aplica as diretrizes do programa nos atendimentos diários, nas avaliaçóes, organização e execução das atividades. Abastece o sistema central e distrital com todos os dados do polo e apresenta as demandas locais às coordenaçôes distritais.

Participaram do estudo 32 trabalhadores do PAS dos nove distritos sanitários de Belo Horizonte, todos PEF:a totalidade dos gestores (seis coordenadores pedagógicos e nove coordenadores distritais) e amostra de profissionais que atuam no atendimento direto aos usuários (17 profissionais) incluídos por sorteio de dois polos de cada um dos oito distritos sanitários. No nono distrito, havia somente um polo e profissional, à época da coleta de dados, e este foi incluído na pesquisa. Não foram sorteados mais participantes, porque se considerou o critério de saturação dos dados para finalizaçáo da coleta (FONTANELLA et. al., 2008), pelo qual se define que objetos,informaçóes e pontos de vista apresentados nas narrativas, ao se tornarem - repetitivos, ficam dispensados de inclusóes posteriores.

A coleta dos dados foi realizada nas próprias academias da saúde, em local reservado, marcadas com antecedência, no horário de preferência dos participantes, por meio de entrevista semiestruturada em profundidade, que continha perguntas objetivas (sobre situação conjugal, de trabalho, profissão, escolaridade e renda) e 
perguntas abertas, a partir de questôes norteadoras não diretivas, iniciada por: "Diga-me o que pensa sobre: Saúde; Doença; Promoção da saúde; Atividade Física; Políticas de promoção de saúde e PAS.” Questôes de relance como: o que é necessário para ter saúde; o que é estar doente; o que você faz para cuidar da saúde, o que é uma pessoa saudável foram incluídas, quando necessárias, para aprofundar algum assunto e propiciar que as representaçôes sobre os temas abordados viessem à tona. As entrevistas foram realizadas por pesquisadores treinados, pertencentes ao Núcleo de Pesquisa e Estudos em Saúde Coletiva - NUPESC - da Escola de Enfermagem da Universidade Federal de Minas Gerais (UFMG).

As entrevistas transcritas foram analisadas pelo método de Análise Estrutural de Narração, proposto por Demazière e Dubar (1997), considerando o princípio de que tudo tem sentido na fala do sujeito, em idas em vindas da narrativa nas quais se encontram disjunçôes e conjunçôes de suas visões de mundo e experiências. A interpretação da narrativa deu-se em dois eixos, um eixo horizontal projetado sobre o eixo vertical, passando de um nível a outro, uma vez que o sentido da narrativa não está no final do discurso, mas no total do corpus (BARTHES, 2008). Para organizar os dados para a análise, utilizou-se a técnica proposta por Blanchet e Gotman (1992), com auxílio do software NVivo $10^{\circ}$.

Primeiramente, fez-se a leitura vertical de cada entrevista, buscando seu sentido global para entender de que se trata a narrativa e qual é seu eixo.

Na segunda etapa, de leitura horizontal, foram realizadas a "desconstrução" e "reconstrução" de cada entrevista. $\mathrm{Na}$ desconstrução, o conteúdo da entrevista individual foi sequenciado $(S)$ e numerado, sendo cada sequência correspondente às afirmaçôes em torno de um assunto. Em cada uma, foram identificados os fatos narrados $(\mathrm{F})$, justificativas e sentimentos $(\mathrm{J})$, além dos personagens ou instituiçôes (P) citados no conjunto do texto. A reconstrução agrupou as sequências que tratavam do mesmo assunto, constituindo-se em categorias empíricas, com nomeação provisória pelo pesquisador, explicitando os significados em torno de cada um dos objetos da narrativa e desvelando as representaçóes em suas concordâncias e discordâncias, por entrevistado.

$\mathrm{Na}$ terceira etapa, foi realizada a leitura transversal, que reúne o conjunto das entrevistas para reorganizar as categorias encontradas, culminando com a categorização final dos assuntos/objetos e suas representaçôes. O resultado dessa etapa é o fechamento das categorias empíricas e a explicitação das representaçôes 
originais e profundas e das representaçôes mais superficiais (GIAMI; VIEL, 1997). Para o fechamento da análise, realizou-se a teorização, com base no referencial teórico e pelo cotejamento das categorias encontradas com achados de outros autores.

Este estudo foi aprovado pelo Comitê de Ética da UFMG, parecer no 501.086, CAAE: 22383013.6.0000.5149, e é parte de um projeto maior intitulado "Academia da saúde: avaliação de programas de atividade física no Brasil”, aprovado pelo Comitê de Ética da Universidade Federal de Pelotas (UFPel), parecer no 151.238, CAAE: 03192412.4.1001.5313.

\section{Resultados e Discussão}

Foram entrevistados 32 profissionais, o que corresponde a $30 \%$ do total de profissionais de educaçáo física no PAS de Belo Horizonte, que inclui as chamadas "Academias da Cidade", nome dado às estruturas similares no município, anteriores ao programa federal. Os coordenadores pedagógicos e distritais (15 entrevistados) apresentaram média de idade de 43,8 anos e 38,2 anos, respectivamente, superior à dos 17 profissionais da assistência entrevistados, com média de 31,7 anos. A média de tempo de atuação nas coordenações do PAS (4,5 anos) também foi muito superior ao dos profissionais da assistência ( 2,8 anos). Identificou-se que a relação trabalhista destes profissionais com a Secretaria Municipal de Saúde se inverte, pois os profissionais da assistência são $100 \%$ efetivados por meio de concurso público ocorrido em 2011 e nos grupos das coordenaçôes, apenas 26,6\% são efetivos, sendo os demais vinculados por meio de contrato. Ressalta-se que o conhecimento relacionado à saúde pública era, na data do concurso, insuficiente ou inexistente nos cursos de graduação. Para ter contato ou aprofundar temas relativos à saúde coletiva era necessário realizar curso de especialização e capacitaçôes oferecidas pelo Ministério da Saúde e da Educação em parcerias com universidades federais do Brasil ou pelas secretarias de saúde dos municípios (FALCI; BELISARIO, 2013). Estas capacitaçóes e treinamentos começaram a ser ofertadas a partir de 2012 e, preferencialmente, para os profissionais que já estavam na rede pública de saúde, atingindo, atualmente, menos de um quarto dos municípios brasileiros que oferecem o PAS (FLORINDO et al., 2016). A cidade de Belo Horizonte tem sido contemplada com estas capacitaçôes desde então.

A interpretação das narrativas evidenciou que os pontos de vista de profissionais de educação física sobre promoção da saúde, modos de vida saudável, atividade 
física e o PAS são condicionados pelas representaçôes sobre saúde e doença, sendo a saúde considerada, de forma mais profunda, o oposto à doença, o que reflete a visão do senso comum (MINAYO; HARTZ; BUSS, 2000). Porém, tais representaçôes já estão convivendo com outras que ampliam os horizontes da prática em saúde, voltada para a construção da promoção da saúde como um bem e um direito. Os profissionais mais antigos no programa, que fizeram capacitações e especializaçóes no campo da saúde pública e da saúde coletiva, têm suas representaçôes originais semelhantes à dos demais profissionais, apontando a dificuldade de modificação de representaçôes profundas, que expressam, de uma forma ou de outra, a maneira como estes profissionais se implicam no serviço e na promoção da saúde da população.

O conjunto das representaçóes sobre saúde e doença compóe as categorias de análise deste estudo.

\section{Representações sobre saúde}

\section{Definiçáo oficial de saúde como necessária para legitimar o trabalho}

Osentrevistados fazem referênciaàs definiçôes de saúdeque estão em documentos, normas públicas ministeriais, diretrizes, paralelamente ao que está consolidado pela ciência, sobretudo a visão biológica de saúde. Nesse sentido, toma-se como discurso oficial aquele dos documentos de órgáos nacionais e internacionais, como o conceito ampliado de saúde de 1986, proposto na Conferência Internacional de Saúde em Ottawa, que inclui os determinantes sociais e a qualidade de vida, tendo a promoção da saúde como principal instrumento para isso (CZERESNIA, 2003; OTTAWA, 1986).

Saúde, além da ausência de doenças, é o estado físico, mental, social de uma pessoa. Envolve fatores sociais, fatores ambientais, contextuais, familiares (CD1).

Ter uma vida fisicamente ativa, evitar fatores de risco, má alimentação, uso de drogas e álcool, uso de tabaco, e ter todos esses determinantes [...] a questáo da violência, da moradia, da educação, isso pra mim é saúde (CD4).

Os modos de vida saudáveis aparecem tanto no discurso oficial da Política Nacional de Promoção da Saúde (BRASIL, 2006) e nos documentos que instituem o PAS (BRASIL, 2011), como no discurso científico, pela comprovada importância da prática de AF como fator de proteção às DCNT e de promoção da saúde (MORA et al., 2007). 
Os PEF pensam a importância do trabalho na atenção básica por meio do discurso científico biológico, paralelamente à ampliação do conceito de saúde, que busca evidências de melhoria das condiçôes de saúde relacionadas às DCNT, como o controle da glicemia e da qualidade de vida dos usuários, considerada desfecho principal da prática regular de AF (SILVA et al., 2017).

Se eu estiver bem, com um bom peso corporal, uma boa pressão arterial, glicemia controlada, parâmetros fisiológicos... Mas, também emocionalmente, bem na família, bem no trabalho, eu estou saudável (PA5).

Melhorar a saúde tem a ver com situação econômica, de moradia, relação no trabalho, relação com amigos, com a família. É o somatório disso. Dentro de um equilíbrio: o lado emocional afetivo, físico, e o lado clínico. [...] e nós fomos formados para trabalhar fora do campo da saúde e, ainda mais, fora desta abrangência toda (CP3).

A relação direta entre saúde, qualidade de vida e a prática de AF tem sido avaliada, em geral, somente por meio de parâmetros fisiológicos e funcionais (BARENGO et al., 2016; MORA et al., 2007), reforçando o discurso científico biológico nas representaçóes de saúde destes profissionais. Esse conhecimento acaba por determinar o fazer dos profissionais que estão no atendimento - a verdade inscrita no discurso científico tem o poder de definir a prática destes profissionais (FOUCAULT, 1979). As contradiçôes sobre saúde e doença e sua determinação biológica persistem no imaginário dos profissionais, e o discurso oficial mais abrangente torna-se, de fato, uma cortina de fumaça que propicia adequação às exigências do sistema, seja em relação ao cuidado com o outro, seja ao próprio cuidado, explicitando a contradição do discurso oficial com a prática de vida e profissional.

Estou em falta com algumas coisas sobre o cuidado com a minha saúde. Eu poderia estar fazendo um treino mais de força, fortalecimento muscular, preocupando com questóes como menopausa, densidade mineral óssea, tudo isso... pensando na força, melhorando a minha questão de saúde (PA3).

Representações originárias do discurso oficial mais abrangente não são, portanto, tão profundas, mas necessárias para justificar a importância de os profissionais de educação física serem incluídos no sistema de saúde e se sentirem defensores de uma proposta considerada inovadora.

$\mathrm{O}$ profissional que trata o indivíduo para que as DCNT não apareçam, que trabalha para tentar melhorar o estilo de vida daquele indivíduo, é o profissional da Educação Física. Entâo, compreender que é muito melhor prevenir do que remediar, que é muito menos dispendioso e mais fácil dar valor ao que fazemos, porque eu acho que houve um ganho muito grande pro SUS(PA5). 
Pautados no discurso científico, tanto o que reforça os aspectos biológicos da saúde e da doença, quanto os que evidenciam sua determinação social, os profissionais defendem sua presença no NASF e no PAS, e afirmam a necessidade de maior investimento estrutural e de condiçóes de trabalho para que a categoria apresente o considerado grande potencial que têm como atores da promoção de saúde. São atitudes de implicação que fortalecem as mudanças, porém com uma carga instituída secularmente no Brasil que facilita a definição de doença e pouco diz da saúde.

\section{Ter saúde é poder viver bem a vida, sem se sentir doente}

A qualidade de vida está presente na narrativa dos entrevistados como uma das principais condiçôes relacionadas à saúde. As representaçóes destes profissionaisestão ancoradas na subjetividade e na amplitude do conceito de qualidade de vida (WHO, 1997), com suas experiências e valores, individuais e coletivos, que incluem os modos de vida que não estão determinados pelo discurso científico da biologia, mas presentes na vida das pessoas com um viés da sociologia funcionalista, o que é gerador de contradiçôes.

Ter saúde é ter condição de vivenciar tudo o que você quer, tudo que você pode, tudo que a vida te propiciar, de forma alegre, feliz, com bem-estar; essa coisa de aproveitar a vida dentro dos seus limites (PA2).

Saúde é a pessoa ter condições de fazer uma atividade física, ter independência, conseguir fazer suas atividades, escolher as coisas, ter autonomia pra fazer as coisas que precisa, sem se sentir doente (PA8).

O sistema de valores e o contexto cultural que determinam a qualidade de vida podem ser identificados nas representaçóes dos entrevistados, que atribuem à qualidade de vida tanto aspectos relacionados à saúde e bem-estar físico expresso no corpo, como aspectos subjetivos que permitem às pessoas "fazer o que se quer" e "ser feliz”. Ter um estilo de vida saudável faz parte da representação das pessoas sobre saúde (MARQUES et al., 2017) e está associado à qualidade de vida (DIAS et al., 2017).

Neste estudo, explicitou-se que a saúde e a qualidade de vida estão asseguradas dentro de um modo de vida que permite à pessoa viver a vida com todos os seus direitos, fazendo o que gosta, porém dentro de certos limites. As representaçôes centradas no dilema entre ser saudável e satisfazer os desejos da vida já foram identificadas em outro estudo (MÁSSIMO; SOUZA; FREITAS, 2015). Existe o 
conflito do "tudo pode" com o "desde que" para ser saudável e ter sua qualidade de vida garantida. Nestes pensamentos subsiste o caráter persistente da sociologia funcionalista médica, apontada por Filho (2011), que afirma a responsabilidade desta corrente no desenvolvimento de "modelos processuais de determinaçâo social da enfermidade que apenas tangencialmente permitem inferir a saúde como resultado de um processo cotidiano de construção de respostas sociais".

A expressão da saúde no corpo das pessoas, para mantê-lo funcional, define-se, na narrativa dos entrevistados, como uma condição para uma vida com qualidade e autonomia.

Ter saúde é ter esses dois critérios contemplados. Ter boa funcionalidade, em todos os aspectos, e satisfaçáo com a vida (PA11).

Existe uma relação entre a qualidade de vida com a percepção de saúde e seus determinantes sociais e subjetivos, capacidade funcional e ausência de doenças (DIAS, 2017). Os instrumentos de avaliação de qualidade de vida englobam aspectos mais sociológicos ou mais relacionados ao estado de saúde biológico das pessoas (MINAYO; HARTZ; BUSS, 2000). Neste estudo, os PEF recorrem tanto a uma abordagem sociológica, de cunho funcionalista, quanto à biomédica, sobre qualidade de vida, em suas representaçóes sobre saúde. Assim, a vida pode e deve ser vivida em sua plenitude, desde que de forma controlada.

Ser saudável é ter liberdade de equilibrar. Não ficar nem muito pra um lado, nem muito pro outro. Equilibrar (CP1).

Há, portanto, a tentativa de trazer o novo por meio de uma visão holística, mantendo-se, porém, velhos modos de pensar a saúde e sua promoção como algo da esfera da objetividade da vida, quando se trata, sobretudo, do coletivo e da doença, e, no máximo, da subjetividade relativa ao sentimento de ser saudável ou não, quando se trata do indivíduo e da saúde, em uma postura institucional mantenedora do status quo da assistência medicalizada à saúde, conformada à ausência de doença. É possível observar, contudo, a crítica necessária e esperada dos PEF sobre medicalização, porque o que fazem é o seu oposto, ao realizarem, junto aos usuários, a prevenção primária até a diminuição ou suspensão do uso de medicamentos, chamada de prevenção quartenária (TESSER, 2017), mas que ainda ocorre de maneira incipiente. Tal prática mostra a busca de uma implicação que se coaduna com as dimensôes mais abrangentes de promoção da saúde propostas no 
PAS, mas seus modos de pensar persistem, como se isto ocorresse de forma mais avançada do que conseguem refletir e se posicionarem em relação à importância destas açóes na perspectiva do Programa.

\section{Representaçóes sobre doença}

\section{Doença é mudança biológica, exige cuidados médicos, medicamentos e aceitaçấo de limitaçóes}

Há representaçôes profundas dos participantes sobre doença, enraizadas na visáo do modelo biomédico do processo saúde e doença, pois a pensam muito mais na perspectiva de uma entidade que requer diagnóstico, cuidados médicos e uso de medicamentos. Esta é uma visão que pode influenciar as práticas de cuidado voltadas mais para as doenças e ao corpo biológico do que ao conjunto da vida das pessoas. De fato, consideram que a doença não é objeto de promoção de saúde.

Estar doente é estar debilitado, precisando de medicamento, de uma atençáo mais curativa de profissionais de saúde, ao invés de buscar ações de prevenção, de promoção (PA3).

Estar doente é uma situação que o seu organismo não consegue responder por si próprio, precisa de medicação, de um cuidado mais especializado, um medicamento (CD9).

Para os entrevistados, a doença é algo que se manifesta no corpo e deve ser medicada.

Estar doente é ter uma doença manifestada, é justamente ter uma doença manifestada que... eh... necessite de cuidados médicos (CD7).

Pode ser um desequilíbrio hormonal, metabólico; é uma doença do corpo. Isso para mim é doença (PA1).

Consideram, também, que a pessoa com doença crônica tem aspectos físicos específicos que definem sua doença, a doença passa a ter "nome" e "cara" e se inscreve na vida dela tornando-se um estigma (GOFFMAN, 1988).

Doença é quando foge dos parâmetros de normalidade (...), desorganização de uma forma geral do organismo, entâo pressão, diabetes, câncer, a pessoa fica com cara de doente... (PA12).

Contraditoriamente, há representaçóes que incluem determinantes sociais como fatores que se relacionam diretamente com a doença, porém se apresentaram somente nas narrativas dos profissionais que estáo na ponta do sistema, no atendimento aos usuários.

Pessoa que não tem condição social de estar alimentando bem está desnutrido, eu acho que isso aí também seria uma pessoa doente (PA12). 
Um problema de trabalho, problema financeiro, isso pra mim pode ser considerado também uma doença, porque pode começar como uma doença psicológica de fundo emocional que pode vir a se tornar uma patologia física. Acho que está tudo interligado (PA6).

Em um contexto mais amplo, os modos de vida saudável desenvolvidos em programas comunitários como o das academias da saúde são representados como favorecedores de saúde, não somente para o tratamento das doenças já existentes, mas para prevenir doenças primárias e secundárias, reduzindo número de mortes relacionadas às DCNT (LEE et al., 2012). São representaçôes que determinam a distinção entre promoção de saúde e prevenção de doenças (WESTPHAL, 2006), em uma vertente mais crítica da promoção da saúde que considera as condiçôes de vida do indivíduo, os determinantes e condicionantes da sua saúde (CARVALHO; COHEN; AKERMAN, 2017). Tais representações ainda estão em construção pelos profissionais do Programa, que trouxeram consigo modos de pensar distantes da promoção de saúde, mas que agora, ao terem uma prática que exige novas posturas, estão se colocando questôes sobre seus modos de pensar antigos. Apesar das contradiçóes explicitadas nas representaçôes dos profissionais, pode-se afirmar que novas práticas vão se incorporando ao cotidiano, por um processo de modificação dos modos de pensar, devido a essas mesmas contradiçôes. Há, então, de um lado, dificuldades de se implicarem de forma questionadora e modificadora de velhas normas, mas, de outro, a defesa das novas normas provenientes do discurso oficial do PAS. Isto define a atual implicação no trabalho e interfere na própria criatividade dos profissionais para dar maior abrangência à promoção da saúde.

\section{Adoecer é se fragilizar e ter limitaçóes}

Ao se referirem às doenças crônicas, a narrativa dos entrevistados é marcada pela falta de atitudes individuais para o autocuidado e prevenção que deveriam aparecer nas diferentes etapas do curso da vida. Do ponto de vista dos entrevistados, o processo natural de envelhecimento se apresenta como um marcador do aparecimento das doenças e fragilidade dos indivíduos. O cuidar da saúde define-se como uma necessidade atrelada ao envelhecimento e possíveis adoecimentos.

Então, eu acho que o cuidado, à medida que envelhecemos, é maior, mais determinado pelo aparecimento da doença, de algum agravo, de algum problema (PA5).

As pessoas mais idosas cuidam melhor da saúde, porque muitas delas já passaram por situaçôes de doença séria. As pessoas, ao sentirem na pele o risco de morrer, ficam com medo e passam a se cuidar melhor (PA6). 
O processo de envelhecimento traz consigo, de fato, redução e comprometimento de vários aspectos biopsicossociais e a $\mathrm{AF}$ se relaciona de forma positiva na prevenção e redução destes (CRUZ et al., 2017; CORDEIRO et al., 2014). Estudo com um grupo de idosos identificou que o significado de envelhecimento estava fortemente relacionado à limitação e doença, condições consideradas negativas (FERREIRA et. al., 2010), o que justificaria, segundo os participantes do presente estudo, a procura de grande número de idosos pelo PAS e a importância das atividades desenvolvidas.

A doença é, portanto, representada como algo que faz parte da vida, porém cerceando o direito e a possibilidade de viver uma vida com qualidade.

Estar doente é o momento que eu estou com aquela limitação, aquele momento que eu tenho que cuidar mais da minha saúde, ter um cuidado especial (PA9).

Doença pra mim é quando você não tem condiçóes de se realizar em qualquer âmbito da sua vida. É também aquela debilidade física mesmo (CP4).

Estudos anteriores identificaram a associação entre doenças crônicas, musculoesqueléticas, respiratórias, entre outras, com as limitaçóes nas atividades habituais e na própria vida (SILVA et al., 2015; FILHA et al.,2015). A limitação do organismo a uma determinada norma lhe confere um estado patológico, que reduz de alguma forma o modo de vida das pessoas, mas que cria um novo modo de viver a vida a partir de sua doença (CANGUILHEM, 2009). Estas doenças exigem adequação a uma nova condiçáo de vida, o que pode permitir repensar a própria vida e viver melhor do que anteriormente. A prática de AF pode contribuir para uma vida com maior qualidade às pessoas que tiveram que readaptar suas vidas à doença com a qual vivem, e segundo os entrevistados, o PAS favorece acesso às pessoas a essa prática.

No conjunto, vislumbra-se, portanto, a possibilidade de quebra do paradigma médico-biológico quando se fala em prevenção e tratamento das DCNT, pelo caminho das mudanças presentes e da promoção da saúde, introjetadas nas representaçóes sobre saúde, porém ainda são modeladas pelas representações de doença. O discurso oficial sobre o processo saúde e doença no Brasil teve avanços substanciais a partir da organização do Sistema Único de Saúde e do modelo de vigilância, mas a prevenção das doenças tem dificuldades em agregar a potencialidade da promoção em saúde na concepção de trabalho dos profissionais, devido à visão biomédica predominante. Ao pautarem as intervençôes do PAS em práticas preventivas que buscam mudança de comportamento, visando à redução de risco, direcionam a responsabilidade ao 
indivíduo e desconsideram os condicionantes e determinantes da saúde relacionados à vulnerabilidade social (AYRES et al., 2006).Temos, neste caso, representaçôes sobre saúde e doença que podem determinar as açôes do PAS com enfoque na prevenção, em que o objetivo é evitar a doença, vinculando-se a uma visão biologicista e comportamentalista deste processo (CARVALHO; COHEN; AKERMAN, 2017).

Há, porém, nas representaçôes destes profissionais, pontos de vista que avançam. Ao considerarem saúde como algo que inclui a autonomia das pessoas, estão considerando alguns princípios da Promoção da Saúde, como equidade, empoderamento, protagonismo do sujeito, dentre outros (WESTPHAL, 2006), paralelamente aos determinantes objetivos das condições de vida, como fundamentais no entendimento do processo saúde e doença. É neste contexto que o PAS se estabelece como uma política de promoção à saúde.

O PAS se configura como um ponto da Rede de Atenção à Saúde, que dá acesso à população em regiôes de maior vulnerabilidade social à $\mathrm{AF}$ e práticas corporais, entre outras açôes de saúde, contribuindo para reduzir desigualdades e iniquidades em saúde. São estas açôes de caráter socioambiental, com sentido emancipatório e visão holística, que rompem com o modelo biomédico reducionista e se configuram como açôes de Promoção da Saúde (CARVALHO; COHEN; AKERMAN, 2017; WESTPHAL, 2006). Os profissionais precisam, entretanto, compreender e se implicar no Programa não somente como um novo posto de trabalho para a categoria, mas pela extensão e perspectiva positiva que o PAS tem para romper, de forma efetiva, com o modelo biomédico e de "promoção de saúde" conservador.

O ideal da promoção em saúde como um caminho a ser percorrido, individual e coletivamente, sofre da valorização maior, histórica, da doença, em detrimento da saúde. Entender estas duas categorias não como contrárias, mas parte da vida, das condiçôes de vida, como queria Canguilhem (2009), ao afirmar que a saúde corresponderia a uma ordem presente tanto na esfera biológica da vida, quanto no modo de vida, parece o ponto de partida para compreender a importância da promoção da saúde. Isto implicaria considerar como as pessoas e a coletividade entendem a saúde, como lutam por ela, como se organizam, e como o Estado responde às demandas e assegura os direitos dos cidadãos. Nesse sentido, a promoção da saúde poderia ser representada como um "seguro social implícito contra os riscos" (FILHO, 2011). 


\section{Considerações finais}

A síntese das representaçóes aponta para pontos de vista direcionados à a mplitude do conceito de saúde, rompendo, ainda que de maneira periférica, com o modelo biomédico. As representaçôes sobre doença, entretanto, criam amarras que as afastam das possibilidades de incluir esta amplitude do conceito de saúde no contexto da promoção de saúde do PAS.

Os resultados mostraram, ainda, que as representaçóes sobre o processo saúde e doença dos coordenadores e profissionais do PAS, que se encontram ainda enraizadas no modelo biomédico, independem do tempo de atuação no programa e da formação que tiveram. Este fato aponta para a força deste modelo na sociedade, além de permitir afirmar que a formação destes profissionais no campo da saúde coletiva não favorece o rompimento da visão biomédica. Porém, foram evidentes os avanços de alguns profissionais, com representaçôes sobre saúde e doença que extrapolam o modelo biomédico, entendendo a importância dos determinantes sociais de saúde e da promoção da saúde neste contexto, além da compreensão de que os aspectos subjetivos das pessoas são fundamentais para a introjeção de representaçôes modificadoras das formas de lidar com a saúde e a doença, mesmo que estas sejam ainda menos fortes que a visão biológica predominante.

A prescrição e a norma se confrontam e tentam se equilibrar entre o viver a vida e ser feliz, e a busca pela saúde como algo que parece contrário a isto. Em meio a estas contradiçóes, o PAS é visto pelos PEF nele envolvidos como uma "das melhores" possibilidades de promover a saúde da população, pois atua em aspectos fisiológicos e sociais, melhorando a qualidade de vida da população. Nessa perspectiva, os PEF do PAS em Belo Horizonte acreditam que a finalidade do programa é atingida e justificam, assim, a necessidade do programa, bem como a importância de suas presenças em todos os níveis, sentindo-se implicados na promoção da saúde.

A interpretação dos dados mostrou que representações centrais fundadas em normas sobre saúde/doença biológicas modelam as práticas destes profissionais, mas que há um caminho possível para se pensar o modelo de promoção da saúde. Esse buscaria a autonomia dos sujeitos sem prescriçóes rígidas, amparadas em representaçôes de autonomia e modos de pensar a vida pelos participantes/usuários do Programa. Parece não haver uma base filosófica presente no cotidiano dos 
profissionais que sustente a promoção da saúde em sua complexidade, de forma a se considerar a estruturação das representações por meio da construção da subjetividade e da relação do sujeito com o mundo. O poder público também deveria levar em conta as subjetividades para avaliar a política pública do programa Academia da Saúde e de seus resultados esperados, reiterando-se que a melhoria dos indicadores relativos às doenças crônicas não transmissíveis está atrelada a aspectos objetivos e subjetivos, individuais e coletivos, seja na implicação dos profissionais na atenção ofertada pelos serviços de saúde, seja no autocuidado da população. ${ }^{1}$

\section{Agradecimentos}

Ao NUPESC-UFMG; Grupo de Estudos em Epidemiologia da Atividade FísicaUFPel; e CNPq- financiamento no 552752/2011-8.

\section{Referências}

ALMEIDA, A. R.; ATHAYDE, F. T. S. Promoção da saúde, qualidade de vida e iniquidade em saúde: reflexōes para a saúde pública. Tempus Actas de Saúde Coletiva, Brasília, v. 9, n. 2, p. 165-172, jun. 2015.

AYRES, J. R. C. M. et al. Risco, vulnerabilidade e práticas de promoção e prevenção da saúde. In: CAMPOS, G.W.S. et al. (Orgs.). Tratado de saúde coletiva. São Paulo: Hucitec; Rio de Janeiro: Fiocruz, 2006, p.375-418.

BARENGO, N. C. et al. Leisure-Time Physical Activity Reduces Total and Cardiovascular Mortality and Cardiovascular Disease Incidence in Older Adults. Journal Of The American Geriatrics Society, v. 65, n. 3, p.504-510, 26 dez. 2016.

BARTHES, R.et al. Análise estrutural da narrativa. Petrópolis: Vozes, 2008. 300p.

BLANCHET, A.; GOTMAN, A. L'enquête et ses méthodes: l'entretien. Paris: Nathan, 1992. 112p. BRASIL. Ministério da Saúde. Departamento de Análise de Situação e Saúde. Secretaria de Vigilância em Saúde. Política Nacional de Promoção da Saúde. Brasília, DF: Ministério da Saúde, 2006. Disponível em: <http://bvsms.saude.gov.br/bvs/publicacoes/politica_promocao_saude. pdf>. Acesso em: 5 mar. 2010.

. Ministério da Saúde. Departamento de Análise de Situaçáo em Saúde. Secretaria de Vigilância Sanitária em Saúde. Avaliação de efetividade de programas de educação física no Brasil. Brasília, DF: Ministério da Saúde, 2013. Disponível em: <http://bvsms.saude.gov.br/bvs/ publicacoes/avaliacao_efetividade_programas_atividade_fisica.pdf>. Acesso em: $31 \mathrm{mar} .2015$. 
- Ministério da Saúde. Departamento de Informática do Sistema Único de Saúde. Secretaria de Atenção Básica. Cadastro Nacional dos Estabelecimentos de Saúde(CNES). Brasília: Datasus, 2017. Disponível em: <http://cnes2.datasus.gov.br/Mod_Ind_Unidade. asp?VEstado=00>. Acesso em: 13 abr. 2018.

- Portaria no 1401, de 15 de junho de 2011. Institui no âmbito da Política Nacional de Atenção Básica, o incentivo para construção de Polos da Academia da Saúde. Brasília, DF: Diário Oficial da União, 15 jun. 2011. Disponível em: <http://bvsms.saude.gov.br/bvs/ saudelegis/gm/2011/prt1401_15_06_2011.html>. Acesso em: 21 ago. 2012.

BUSS, P. M.; PELLEGRINI FILHO, A. A saúde e seus determinantes sociais. Physis: Revista de Saúde Coletiva. Rio de Janeiro, v. 1, n. 17, p.77-93, 2007.

CANGUILHEM, G. O normal e o patológico. 6. ed. Rio de Janeiro: Forense Universitária,2009. 154p.

CARVAlHO, F. F. B.; COHEN, S. C.; AKERMAN, M. Refletindo sobre o instituído na Promoção da Saúde para problematizar “dogmas”. Saúde em Debate, v. 41, n. 3, p.265-276, set. 2017.

CORDEIRO, J.et al. Efeitos da atividade física na memória declarativa, capacidade funcional e qualidade de vida em idosos. Revista Brasileira de Geriatria e Gerontologia, v. 17, n. 3, p.541552, set. 2014.

CRUZ, D. T. et al. Factors associated with frailty in a community-dwelling population of older adults. Revista de Saúde Pública, v. 51, p.1-13, 27 nov. 2017.

CZERESNIA, D. O conceito de saúde e a diferença entre prevenção e promoção. In: CZERESNIA, D.; FREITAS, C. M. (Orgs.).Promoção da saúde: conceitos, reflexóes, tendências. Rio de Janeiro: mFiocruz, 2003, p. 39-53.

DEMAZIÈRE, D.; DUBAR, C. Analyser les entretiens biographiques, l'exemple de récits d'insertion. Paris: Nathan, Coll. Essais \& Recherches, 1997. 287p.

DIAS, J. et al. Physical activities practicing among scholar professors: focus on their quality of life. Escola Anna Nery, v. 21, n. 4, p.1-6, 23 out. 2017.

FALCI, D. M.; BELISÁRIO, S. A. A inserção do profissional de educação física na atenção primária à saúde e os desafios em sua formação. Interface: Comunicação Saúde Educação. Botucatu, v. 17, n.47, p. 885-899, 2013.

FERREIRA, O. G. L. et al. Significados atribuídos ao envelhecimento: idoso, velho e idoso ativo. Psico-USF, v. 15, n. 3, p. 357-364,2010.

FILHA, M. M. T. et al. Prevalência de doenças crônicas não transmissíveis e associação com autoavaliação de saúde: Pesquisa Nacional de Saúde, 2013. Revista Brasileira de Epidemiologia, v. 18, n. 2, p.83-96, dez. 2015. 
FILHO, N. A. Capitulo 18 Epistemologia da Saúde: do problema de Kant-Gadamerà Teoria dos Modos de Saúde. Disponível em:<https://filosofiasaudedoencacuidado.wordpress. com/2011/12/09/capitulo-18-epistemologia-da-saude-do-problema-de-kant-gadamer-a-teoriados-modos-de-saude-naomar-de-almeida-filho/>. 2011.

FLORINDO, A. et al. Description of health promotion actions in Brazilian cities that received funds to develop "Academia da Saúde" program. Brazilian Journal of Kinanthropometry and Human Performance, v. 18, n. 4, p.483-492, 19 set. 2016.

FONTANELLA, B. J. B. et al. Amostragem por saturação em pesquisas qualitativas em saúde: contribuiçôes teóricas. Caderno de Saúde Pública, v. 24, n. 1, p. 17-27, 2008.

FOUCAULT, M. Microfísica do poder. Rio de Janeiro: Ediçôes Graal, 1979. 174p.

GIAMI, A.; VEIL, C. Enfermeiras frente à aids: representaçóes e condutas, permanência e mudanças. Canoas: ULBRA, 1997. 333p.

GOFFMAN, E. Estigma: notas sobre a manipulação da identidade deteriorada. Rio de Janeiro: Guanabara Koogan, 1988. 118p.

GUARDA, F. R. B. da et al. Intervenção do profissional de educação física: formação, perfil e competências para atuar no Programa Academia da Saúde. Revista Pan-amazônica de Saúde, v. 5, n. 4, p. 63-74, dez. 2014.

LAS CASAS, R. C. R. et al. O profissional de educação física no sistema único de saúde de Belo Horizonte. In: NOCE, F. et al.(Orgs.). O profissional de educação física na área da saúde. PróSaúde, Pet-Saúde, Universidade Federal de Minas Gerais. 2014, 173p. Disponível em: <https:// www.researchgate.net/publication/280579683_O_Profissional_de_Educacao_Fisica_na_ area_da_Saude>. Acesso em: 14 fev. 2015.

LEE, I. M. et al. Impact of Physical Inactivity on the World's Major Non-Communicable Diseases. Lancet, v. 380, n. 9838, p. 219-229, 2012.

LOURAU, R. Implicação-Transdução. In:ALTOÉ, S. (Org.).René Lourau: analista institucional em tempo integral. São Paulo: Hucitec,2004, p. 212-223.

MARQUES, M. C. M. P.; MENDES, F. R. P.; SERRA, I. C. C. Estilos de vida: representaçóes sociais construídas por doentes com infarto do miocárdio e familiares. Revista Gaúcha de Enfermagem, v. 38, n. 2, 2017.

MÁSSIMO, E. A. L.; SOUZA, H. N. F. de; FREITAS, M. I. F. Chronic non-communicable diseases, risk and health promotion: social construction of Vigitel participants. Ciência \& Saúde Coletiva, v. 20, n. 3, p.679-688, mar. 2015.

MINAYO, M. C. S. Análise qualitativa: teoria, passos e fidedignidade. Ciência e Saúde Coletiva, v. 17, n. 3, p.621-626, 2012. 
MINAYO, M. C. S.; HARTZ, Z. M. A.; BUSS, P. M. Qualidade de vida e saúde: um debate necessário.Ciência e Saúde Coletiva, v. 5, n.1, p.7-18, 2000.

MORA, Samia et al. Physical Activity and Reduced Risk of Cardiovascular Events: Potential Mediating Mechanisms. Circulation, v. 9, n. 116, p.2110-2118, 2007.

OTTAWA. Carta de Ottawa. In: PRIMEIRA CONFERÊNCIA INTERNACIONAL SOBRE PROMOÇÃO DA SAÚDE. Anais... Canadá: Ottawa, 1986. Disponível em: <http:// bvsms.saude.gov.br/bvs/publicacoes/carta_ottawa.pdf>. Acesso em: 9 set. 2016.

REIS, R. S. et al. Promoting Physical Activity Through Community-Wide Policies and Planning: Findings from Curitiba, Brazil. Journal of Physical Activity and Health, v. 7, n. 2, p.137-145, jul. 2010.

SILVA, F. C.et al. Ejercicio físico, calidad de vida y salud de diabéticos tipo 2. Journal Of Sport Psychology, v. 26, n. 1, p.13-25, 2017.

SILVA, M. da; PICASSO, C. L. M.; ROSITO, M. P. Epidemiological profile of workers with musculoskeletal disorders of a supermarket company. Fisioterapia em Movimento, v. 28, n. 3, p. 573-581, set. 2015.

TESSER, C. D. Por que é importante a prevenção quaternária na prevenção? Revista de Saúde Pública, v. 51, p.1-9, 4 dez. 2017.

WESTPHAL, M.F. Promoção da saúde e prevenção de doenças. In: CAMPOS, G.W.S.; MINAYO, M.C.S.; AKERMAN, M.; DRUMOND JÚNIOR, M.; CARVALHO, Y.M. (Org.). Tratado de saúde coletiva. São Paulo: Hucitec; Rio de Janeiro: Ed. Fiocruz, 2006, p.635-667.

WORLD HEALTH ORGANIZATION. Measuring Quality of Life - The Whoqol-100 and the Whoqol-Bref. Geneva, Switzerland, 1997. 15p. Disponível em: <http://www.who.int/ mental_health/media/68.pdf>. Acesso em: 9 out. 2017.

\section{Nota}

${ }^{1}$ A.M.S. Ivo realizou a concepçáo e delineamento da pesquisa, coleta, análise e interpretação dos dados e redaçáo do artigo. D. C. Malta participou da concepçáo da pesquisa, discussão e revisão do artigo. M. I. de F. Freitas foi responsável pela concepção, delineamento e coordenação da pesquisa, análise e interpretação dos dados, redação e revisão do artigo. 


\section{Abstract}

\section{Modes of thinking of the professionals of the Health Academy Program about health and disease and their implications in actions of health promotion}

The Health Academy Program was created to contribute to health promotion, care production and improvement of access to the practice of physical activity, based on the holistic view of care. Aim: to understand the HAP professionals' representations about health/disease and its implications for health promotion activities. A qualitative study based on the theory of Social Representations, understanding them as the points of view, which are explicit in human action. In-depth interviews with physical education professionals from the PAS of Belo Horizonte were interpreted by the Structural Analysis of Narration. Results: There are central representations that define health as the opposite of disease, and, peripherally, health is more than absence of disease. The biomedical model coexists with viewpoints that expand health practice, focused on the construction of health promotion as a good and a right. The representations remain parallel, use the official discourse that created the Program, supported by Collective Health, and the discourse of science and common sense, supported by Biology. The implication of the professional in the actions is paradoxical, and requires improvements in their training to continue the paradigm shift in health care.

> Keywords: health promotion; public policies; qualitative research; Collective Health; program evaluation. 